\title{
Plasma immersion ion implantation of boron for ribbon silicon solar cells
}

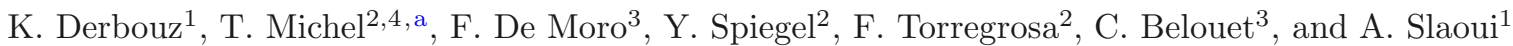 \\ 1 InESS-CNRS-Univ. Strasbourg, France \\ IBS, Peynier, France \\ 3 Solarforce, Bourgoin-Jallieu, France \\ 4 Université d'Aix-Marseille, Institut Fresnel, Marseille, France
}

Received: 18 September 2012 / Accepted: 5 April 2013

Published online: 10 September 2013

(C) Derbouz et al., published by EDP Sciences, 2013

\begin{abstract}
In this work, we report for the first time on the solar cell fabrication on n-type silicon RST (for Ribbon on Sacrificial Template) using plasma immersion ion implantation. The experiments were also carried out on FZ silicon as a reference. Boron was implanted at energies from 10 to $15 \mathrm{kV}$ and doses from $10^{15}$ to $10^{16} \mathrm{~cm}^{-2}$, then activated by a thermal annealing in a conventional furnace at 900 and $950{ }^{\circ} \mathrm{C}$ for 30 min. The $\mathrm{n}^{+}$region acting as a back surface field was achieved by phosphorus spin-coating. The frontside boron emitter was passivated either by applying a $10 \mathrm{~nm}$ deposited $\mathrm{SiO}_{X}$ plasma-enhanced chemical vapor deposition (PECVD) or with a $10 \mathrm{~nm}$ grown thermal oxide. The anti-reflection coating layer formed a $60 \mathrm{~nm}$ thick $\mathrm{SiN}_{X}$ layer. We show that energies less than $15 \mathrm{kV}$ and doses around $5 \times 10^{15} \mathrm{~cm}^{-2}$ are appropriate to achieve open circuit voltage higher than $590 \mathrm{mV}$ and efficiency around $16.7 \%$ on FZ-Si. The photovoltaic performances on ribbon silicon are so far limited by the bulk quality of the material and by the quality of the junction through the presence of silicon carbide precipitates at the surface. Nevertheless, we demonstrate that plasma immersion ion implantation is very promising for solar cell fabrication on ultrathin silicon wafers such as ribbons.
\end{abstract}

\section{Introduction}

Even with the new rising solar cell generations, crystalline silicon modules still dominate the market with about $80 \%$ of the global production capacity [1]. While improving the cell efficiency is the key to producing more watts per cell, manufacturing cost reduction and factory output continue to drive down the cost of photovoltaics (PV). In this way reducing the substrate cost is of great importance. One recent innovation is the use of thin silicon ribbons. Thin Si ribbons made by Solarforce using RST technology [2], allows a decrease in the consumption of silicon down to 1 to $2 \mathrm{~g} / \mathrm{Wp}$ achieving costs below $0.2 € / \mathrm{Wp}$, and cells as thin as $60 \mu \mathrm{m}$.

Figure 1 shows the schematic of the ribbon growth method which is characterized by a vertical growth direction combined with the use of a substrate [3]. This results in a growth speed of about $3-8 \mathrm{~cm} / \mathrm{min}$; much faster than edge-defined film-fed growth (EFG) and string ribbon (SR) growth. Thus so far RST ribbon up to $8 \mathrm{~cm}$ in width can be grown with a thickness down to $80 \mu \mathrm{m}$. Another feature of the RST material is the low concentration of interstitial oxygen $\left(<10^{17} \mathrm{~cm}^{-3}\right)$ and substitutional car-

\footnotetext{
${ }^{a}$ e-mail: thomas.michel@ion-beam-services.fr
}

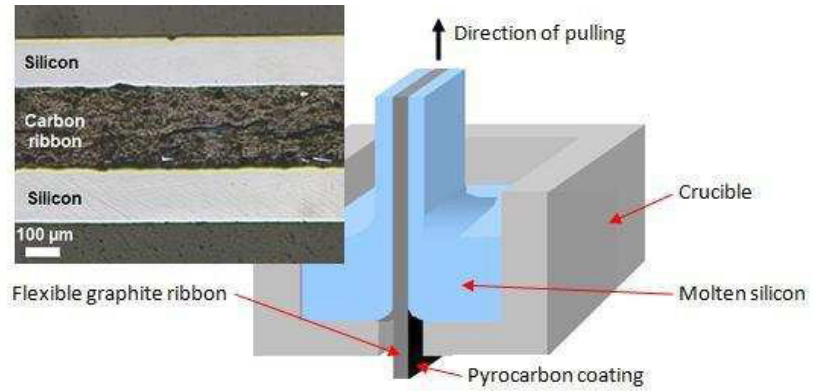

Fig. 1. Schematic views of the RST ribbon growth method and of a cross section of the resulting structure.

bon $\left(\approx 5 \times 10^{17} \mathrm{~cm}^{-3}\right)$. It is also possible to obtain either p-type or n-type silicon by simply changing the doping type of the Si precursor.

As for solar cells fabrication on these thin Si ribbons, the emitter can be processed from a gas or liquid source followed by a drive-in step. A high temperature and long duration process is often needed, especially for boron diffusion, which results in a highly surface concentrated doping profile. On the other hand, ion implantation can offer a better control of the concentration and depth of the doping distribution. While assuring great process uniformity 


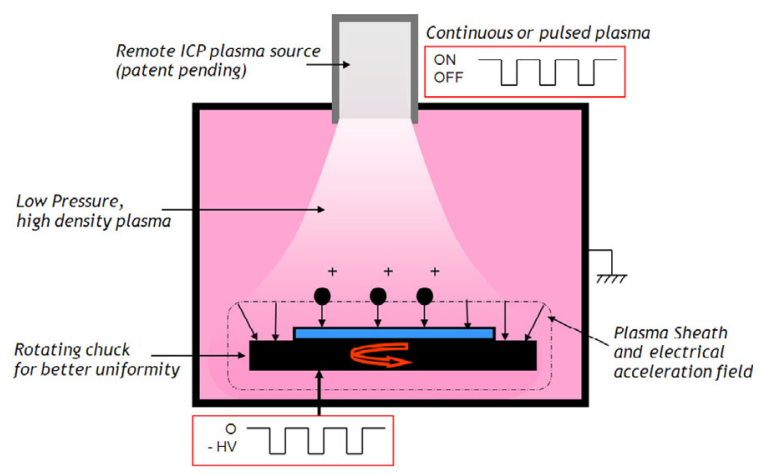

Fig. 2. PULSION ${ }^{\circledR}$ doping tool design.

and reproducibility, ion implantation also leads to cell binning improvements [4]. Whereas classical beamline implanters do not meet the future PV industry requirements in terms of cost and productivity, new types of equipment such as plasma immersion ion implantation (PIII) reactors promise higher throughput.

Figure 2 presents the PULSION ${ }^{\circledR}$ plasma immersion tool designed by IBS. PULSION's unique features allow large-area implantations of high doses with a very high throughput, but also enable conformal doping of textured or grooved structures. Providing a better accuracy and control of concentration and depth without dead layer, PULSION ${ }^{\circledR}$ doping allows a decrease of the emitter saturation current, an enhancement of the blue response, and thus the increase of cell efficiency. After implantation, the dopants require an activation step. Furnace annealing offers the capability to grow a high quality thermal oxide for the emitter passivation. Furthermore, this emitter engineering sequence reduces manufacturing costs by eliminating the edge isolation step and the phosphosilicate glass removal.

We present for the first time results on n-type RST ribbon silicon cell process based on Boron plasma implanted emitter using PULSION ${ }^{\circledR}$. Many results presented here concern n-type FZ silicon which acts as a reference to set the experimental parameters and to validate each step of the fabrication process flow. PULSION ${ }^{\circledR}$ doping is well suited for emitter doping, especially boron diffusion which is known to be more complicated than phosphorus. Boron was implanted through $\mathrm{BF}_{3}$ gas precursor at energies from 10 to $15 \mathrm{kV}$ and doses from $10^{15}$ to $10^{16} \mathrm{~cm}^{-2}$. We first investigated the dependence of the sheet resistance of the p emitter on implant (energy $E$ and dose $D$ ) and annealing conditions (temperature $T$ and time $t$ ).

\section{Experimental}

The as-grown n-type RST silicon wafers, with a resistivity of $1.5-4.0 \Omega \mathrm{cm}$ and $80-140 \mu \mathrm{m}$ thick, were etched in a solution ( $\mathrm{HF}: \mathrm{HNO}_{3}: \mathrm{CH}_{3} \mathrm{COOH}-1: 7.5: 2.5$ vol.) and ultrasonic bath to remove the $\mathrm{SiC}$ backside layer, which was in contact with the carbon ribbon during the silicon ribbon growth. The n-type FZ silicon wafers with a resistivity of $2 \Omega \mathrm{cm}$ and $260 \mu \mathrm{m}$ thick were RCA-cleaned before implantation and annealing.

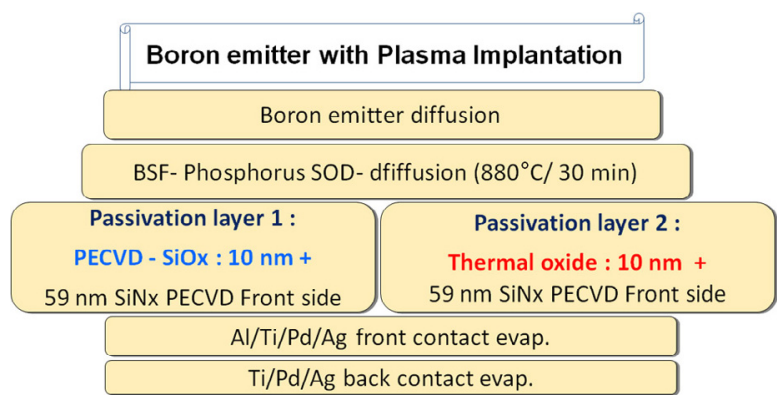

Fig. 3. Flow chart of n-type RST ribbon and FZ.

Figure 3 shows the flow charts for the fabrication of solar cells on RST-Si and FZ-Si samples: after chemical cleaning, the boron emitter was formed by plasma implantation. The boron was implanted at energies from 10 to $15 \mathrm{kV}$ and doses from $10^{15}$ to $10^{16} \mathrm{~cm}^{-2}$. The activation of Boron was carried out by thermal annealing in a conventional furnace at 900 and $950{ }^{\circ} \mathrm{C}$ for $30 \mathrm{~min}$. As a second step, a Phosphorus doped solution (P509 from Filmtronics) was spun at the back of the RST sheets and then annealed at $880{ }^{\circ} \mathrm{C}$ for 30 min to form the $\mathrm{n}^{+}$doped region, which acts as a back surface field (BSF). After a HF-clean to remove the silicate glass layers, a plasma hydrogenation was performed at $400{ }^{\circ} \mathrm{C}$ for $2 \mathrm{~h}$ on the back side (through the BSF region). This process aims to passivate some dangling bonds and defects within the bulk such as grain boundaries.

The frontside boron emitter was passivated either by a $10 \mathrm{~nm} \mathrm{SiO}_{X}$ deposited by PECVD or a $10 \mathrm{~nm}$ thermal oxide. The anti-reflection coating (ARC) layer was formed by deposition of a $60 \mathrm{~nm} \operatorname{SiN}_{X}$ layer. The metallic contacts are patterned by photolithography. The front contacts were formed onto the silicon emitter surface with a stack of a $100 \mathrm{~nm}$ thick Al layer, a $50 \mathrm{~nm}$ thick Ti layer, a $50 \mathrm{~nm}$ thick Pd layer and $1 \mu \mathrm{m}$ thick Ag layer. The backside contacts were achieved by stacking $50 \mathrm{~nm}$ of Ti, $50 \mathrm{~nm}$ of $\mathrm{Pd}$ and $1 \mu \mathrm{m}$ of $\mathrm{Ag}$. All cells were annealed at $350{ }^{\circ} \mathrm{C}$ for $30 \mathrm{~min}$ under forming gas $\left(90 \% \mathrm{Ar}\right.$ and $\left.10 \% \mathrm{H}_{2}\right)$ ambient in a conventional furnace. The samples were then cut into small cells (about $1.5 \mathrm{~cm}^{2}$ ) using a saw disk.

The cells were then analysed using $I-V$ illumination set-ups (ORIEL spectrum and Sun-Voc Sinton) under AM1.5G radiation, as well as by spectral response measurements.

\section{Results and discussion}

The sheet resistance $R_{s q}$ was measured for the $\mathrm{p}^{+}$front emitter made on FZ silicon as a function of implantation and annealing conditions. The results are shown in Figure 4. Annealing the plasma implanted samples at $900{ }^{\circ} \mathrm{C}$ results in a sheet resistance of about $120-140 \Omega /$ sq. Higher energy $E$ or higher dose $D$ results in lower sheet resistances. On the other hand, an annealing at $950{ }^{\circ} \mathrm{C}$ for $30 \mathrm{~min}$ allows sheet resistance values as low as $70 \Omega / \mathrm{sq}$.

As expected, a more efficient boron activation is obtained with high temperature annealing. Such low $R_{\mathrm{sq}}$ values are appropriate for solar cell fabrication. 
K. Derbouz et al.: Plasma immersion ion implantation of boron for ribbon silicon solar cells

Table 1. Extraction of $V_{\mathrm{OC}}, J_{\mathrm{SC}}, \mathrm{FF}$ and $\eta$ from $I-V$ measurement using Oriel and SunVoc (SINTON) setups.

\begin{tabular}{|c|c|c|c|c|c|c|c|}
\hline Silicon & $\begin{array}{l}\text { PIII Boron } \\
\text { Emitter (IBS) }\end{array}$ & $\begin{array}{l}\text { Passivation } \\
\text { layer }\end{array}$ & Setup & $\begin{array}{l}V_{O C} \\
(\mathrm{mV})\end{array}$ & $\begin{array}{c}J_{S C} \\
\mathrm{~mA} / \mathrm{cm}^{2}\end{array}$ & $\begin{array}{l}\mathrm{FF} \\
(\%)\end{array}$ & $\begin{array}{c}\eta \\
(\%)\end{array}$ \\
\hline Fz-Si-1 & BF3: & PECVD & Oriel & 593.1 & 38.8 & 70.1 & 16.1 \\
\hline $200 \mu \mathrm{m}$ & $E: 8 \mathrm{kV}$ & & & & & & \\
\hline $2 \Omega \mathrm{cm}$ & $D: 5 \times 10^{13} \mathrm{~cm}^{-2}$ & $\mathrm{SiO}_{X}+\mathrm{SiN}_{X}$ & Sun-Voc & 582.0 & & 75,2 & 16.9 \\
\hline Fz-Si-2 & BF3: & PECVD & Oriel & 596.9 & 38.7 & 69.3 & 16.7 \\
\hline $200 \mu \mathrm{m}$ & $E=15 \mathrm{kV}$ & & & & & & \\
\hline $2 \Omega \mathrm{cm}$ & $D=5 \times 10^{15} \mathrm{~cm}^{-2}$ & $\mathrm{SiO}_{X}+\mathrm{SiN}_{X}$ & Sun-Voc & 586.0 & & 75.0 & 17.7 \\
\hline Fz-Si-2 & BF3: & Thermal & Oriel & $559: 1$ & 36.2 & 63.4 & 12.9 \\
\hline $200 \mu \mathrm{m}$ & $E=15 \mathrm{kV}$ & & & & & & \\
\hline $2 \Omega \mathrm{cm}$ & $D=1 \times 10^{16} \mathrm{~cm}^{-2}$ & $\mathrm{SiO}_{2}+\mathrm{SiN}_{X}$ & Sun-Voc & 555.0 & & 73.3 & 14.7 \\
\hline n-RST & BF3: & Thermal & Oriel & 534.0 & 27.4 & 55.7 & 82 \\
\hline $100 \mu \mathrm{m}$ & $E=15 \mathrm{kV}$ & & & & & & \\
\hline $2 \Omega \mathrm{cm}$ & $D=5 \times 10^{15} \mathrm{~cm}^{-2}$ & $\mathrm{SiO}_{2}+\mathrm{SiN}_{X}$ & Sun-Voc & 532.0 & & 68.6 & 10.0 \\
\hline
\end{tabular}

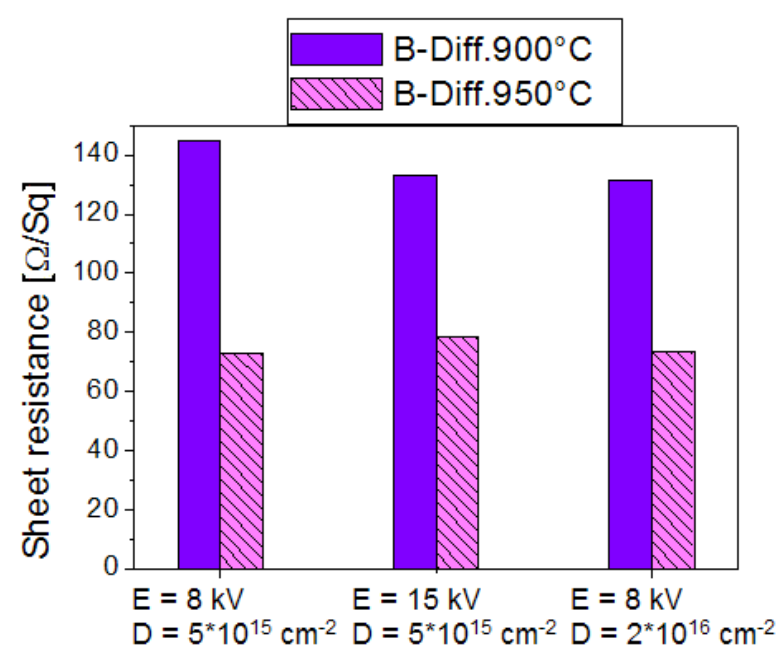

Fig. 4. Sheet resistance of boron implanted emitters as a function of implantation and annealing conditions.

Figures 5 and 6 plot open circuit voltages $\left(V_{\mathrm{OC}}\right)$ and conversion efficiencies $(\eta)$ values as a function of implant conditions and thermal annealing for solar cells made on n-type FZ silicon wafers.

These data show that the best conditions to reach the highest values are an energy $E=15 \mathrm{kV}$ and dose $D=5 \times 10^{15} \mathrm{~cm}^{-2}$ combined with a thermal activation at $950^{\circ} \mathrm{C}$ for $30 \mathrm{~min}$ in order to optimize the activation of the dopants. The best $V_{\mathrm{oc}}$ is approaching $600 \mathrm{mV}$ and the efficiency is close to $17 \%$. It has to be noticed that neither plasma immersion implantation nor annealing were optimised. Therefore much better solar cell performances were expected with these optimisations and the implementation of a surface texturization.

Table 1 gives the values of open circuit voltage $V_{\mathrm{OC}}$, short circuit current density $J_{\mathrm{SC}}$, fill factor $\mathrm{FF}$, and efficiency $\eta$, extracted from the $I-V$ characteristics under AM1.5G illumination.

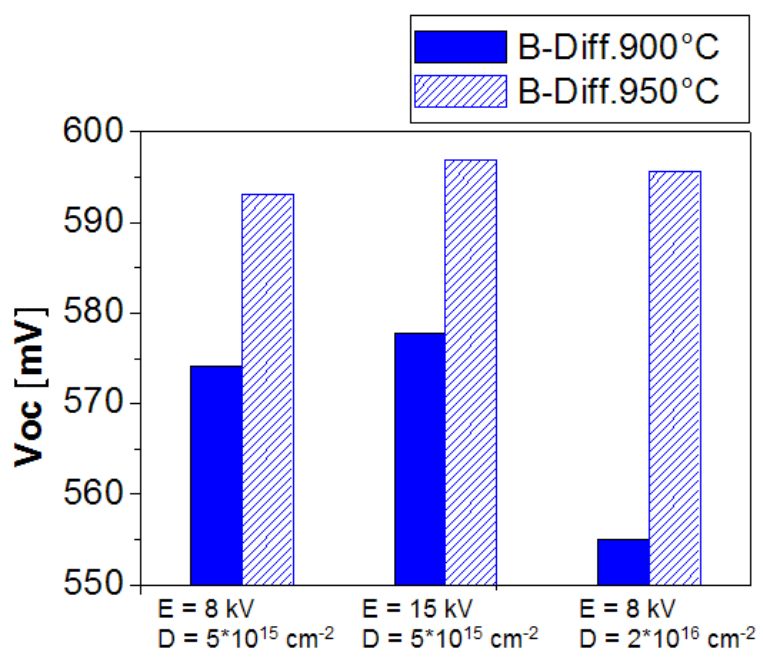

Fig. 5. Extraction of open circuit voltage of PULSION ${ }^{\circledR}$ boron emitter solar cells on FZ wafers.

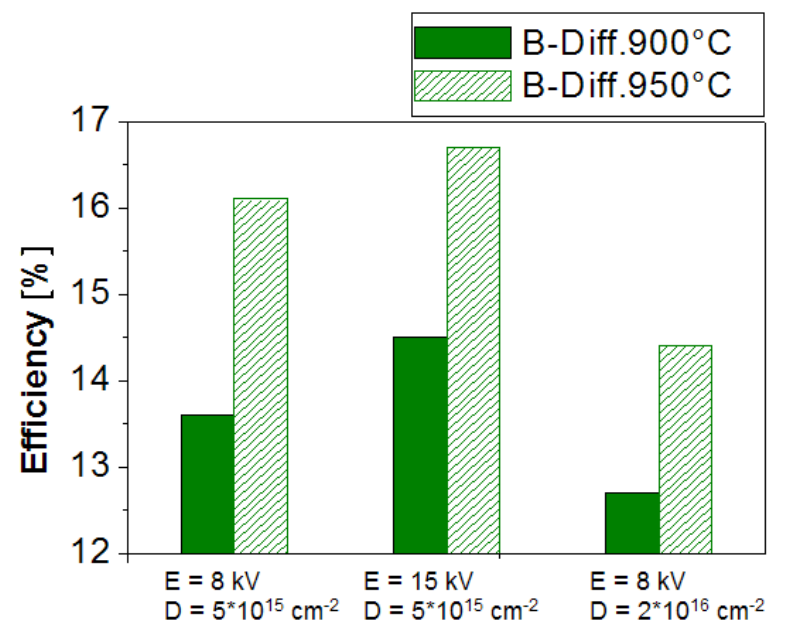

Fig. 6. Efficiency $\eta$ of the PULSION ${ }^{\circledR}$ boron emitter solar cells on FZ wafers. 


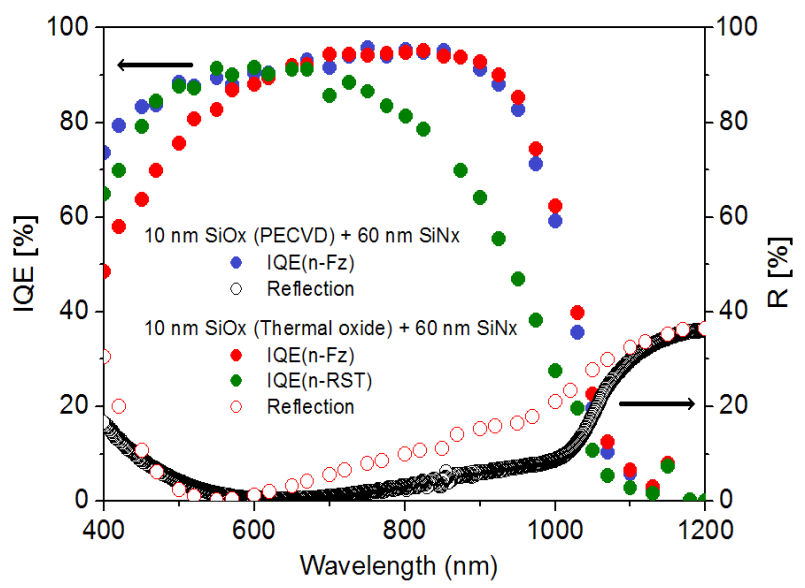

Fig. 7. Spectral responses (IQE and reflectance) on $\mathrm{n}-\mathrm{FZ}$ and n-RST silicon.

The solar cells passivated with the $\mathrm{SiO}_{Y} / \mathrm{SiN}_{X}$ stack performed by PECVD show a higher conversion efficiency compared to those passivated by the $\mathrm{SiO}_{2}$ (thermal)/ $\mathrm{SiN}_{X}$ stack. These low performances are mainly caused by the implementation of an oxidizing annealing aiming to grow a thin passivating oxide. We have observed a degradation of the material lifetime due to aggressive cooling ramps of the annealing. We assume that, with such high impurity concentration, boron diffusion into the oxide during annealing should also be detrimental for the emitter passivation through the probable surface depletion of the boron emitter [5]. Further experiments are expected to improve the boron emitter passivation.

The RST-Si based cells suffer from a low FF which might be due to some shunts in the bulk of the material as well as due to the presence of residual $\mathrm{SiC}$ precipitates that partially shunt the emitter. As a result, the cell efficiency of the n-type ribbon based cell made by this method is about $8.2 \%$.

To get a better insight on the limiting factors of the quality of the cells, spectral responses were measured. Figure 7 plots the internal quantum efficiency (IQE) and the reflectance of the n-type ribbon and FZ silicon solar cells. The strong drop of the IQE in the short wavelength range (below $600 \mathrm{~nm}$ ) for both passivation conditions means that the passivation of the boron emitter is not good enough. The emitter region can obviously be improved by lowering the doping level at the surface while maintaining a good sheet resistance and by optimising the surface passivation of the emitter by depositing an $\mathrm{Al}_{2} \mathrm{O}_{3}$ layer.

In the near-infrared region, the response of the n-RST solar cell is quite poor compared to that of FZ silicon, which is probably due to a low minority carrier lifetime. The effective minority carrier diffusion length value
$\left(L_{\text {eff }}\right)$ deduced from the spectral response of the RST cell is of about $68 \pm 5 \mu \mathrm{m}$, which is lower than the RST ribbon thickness (about $90 \mu \mathrm{m}$ ). This extracted diffusion length value corresponds to an effective minority carrier lifetime between 3 and $5 \mu$ s if we consider a diffusivity of about $10 \mathrm{~cm}^{2} / \mathrm{s}$. It was noticed that the back surface field insured by the phosphorus doped region should be likely to improve.

\section{Summary}

This work presents the perspective of forming boron emitter in n-type silicon by the promising technique of plasma immersion ion implantation. Required sheet resistance values can be obtained by choosing appropriate implant conditions and thermal budget for damage removal and electrical activation of boron. Solar cells with efficiencies approaching 17\% on FZ silicon have already been achieved without specific optimisation of the operational parameters. The cells still suffer from low quality passivation. The first attempts to make solar cells on n-type ribbon silicon resulted in efficiencies a bit above $8 \%$. We demonstrate that performances of such cells are limited by recombinations at the surface and in the bulk. The presented preliminary results using the PULSION ${ }^{\circledR}$ tool show that further improvement in ribbon material quality and cell processing, such as bulk hydrogenation, will allow cell efficiency to reach above $15 \%$ for a $100 \mu \mathrm{m}$ thick ribbon using a very simple process.

Finally, the capability of PULSION ${ }^{\circledR}$ to implant Boron as well as Phosphorus could offer the perspective to reduce manufacturing costs by easily performing all doping steps followed by a single common annealing.

This work was partially funded by the Agence de l'Environnement et de la Maîtrise de l'Énergie (ADEME), France, under project DEMOS; the coordinator of the project is Solarforce.

\section{References}

1. European Photovoltaic Industry Association (EPIA), Solar Generation 6, 20 (2011)

2. Solarforce S.A., Ribbon Technology, http://www. solarforce.fr/en/technology.html

3. C. Belouet, J. Cryst. Growth 82, 110 (1987)

4. A. Gupta et al., in Proc. 25th EU PVSEC, Valencia, Spain, 2010, pp. 1158-1162

5. J. Benick et al., in Proc. 33rd IEEE PVSC, San Diego, CA, USA, 2008, pp. 1-5 